\title{
Epigenetic DNA Demethylation Causes Inner Ear Stem Cell Differentiation into Hair Cell-Like Cells
}

\author{
Yang Zhou and Zhengqing $\mathrm{Hu}^{*}$ \\ Department of Otolaryngology-Head and Neck Surgery, Wayne State University School of Medicine, Detroit, MI, USA
}

The DNA methyltransferase (DNMT) inhibitor 5-azacytidine (5-aza) causes genomic demethylation to regulate gene expression. However, it remains unclear whether 5-aza affects gene expression and cell fate determination of stem cells. In this study, 5-aza was applied to mouse utricle sensory epithelia-derived progenitor cells (MUCs) to investigate whether 5-aza stimulated MUCs to become sensory hair cells. After treatment, MUCs increased expression of hair cell genes and proteins. The DNA methylation level (indicated by percentage of 5 -methylcytosine) showed a $28.57 \%$ decrease after treatment, which causes significantly repressed DNMT1 protein expression and DNMT activity. Additionally, FM1-43 permeation assays indicated that the permeability of

OPEN ACCESS

Edited by:

Michael E. Smith,

Western Kentucky University, USA

Reviewed by:

Paola Tognini,

University of California, Irvine, USA

Jian Zuo,

St. Jude Children's Research Hospital,

USA

Tian Ren

Oregon Health \& Science University,

USA

*Correspondence:

Zhengqing $\mathrm{Hu}$

zh@med.wayne.edu

Received: 06 January 2016 Accepted: 12 July 2016 Published: 03 August 2016

Citation:

Zhou Y and Hu Z (2016) Epigenetic DNA Demethylation Causes Inner Ear

Stem Cell Differentiation into Hair Cell-Like Cells.

Front. Cell. Neurosci. 10:185. doi: 10.3389/fncel.2016.00185 5-aza-treated MUCs was similar to that of sensory hair cells, which may result from mechanotransduction channels. This study not only demonstrates a possible epigenetic approach to induce tissue specific stem/progenitor cells to become sensory hair cell-like cells, but also provides a cell model to epigenetically modulate stem cell fate determination.

Keywords: 5-azacytidine, DNA demethylation, epigenetics, hair cell, methylation, stem cell

\section{INTRODUCTION}

In mammals, inner ear sensory hair cell damage is a major health problem causing deafness or hearing impairments to $\sim 10 \%$ of the population, which are usually induced by loud sound, aging, aminoglycoside drug exposure, diseases, and genetic disorders (Basner et al., 2015; Parker and Bitner-Glindzicz, 2015; Wong and Ryan, 2015). Previous studies revealed that non-mammalian vertebrates have the capability to repair injured sensory hair cells; however, this self-repair ability is severely limited in mammals (Jia et al., 2009; Oesterle, 2013). Recent studies suggest that stem cells may be a possible cell source for mammalian sensory hair cell regeneration (Okano and Kelley, 2012; Ronaghi et al., 2012). For instance, mouse embryonic stem cells have been induced to nonneural ectoderm, preplacodal ectoderm, and otic vesicle epithelia, which eventually develop into cell clusters containing hair cells and supporting cells (Koehler and Hashino, 2014). Tissue specific stem/progenitor cells have been isolated from adult mouse utricle sensory epithelia and expressed markers shown in prosensory cells, which are hair cell stem cells during otic vesicle development.

Abbreviations: MUC, adult mouse utricle sensory epithelial derived progenitor cells; 5-aza, 5-azacytidine; MeDIP, methylated DNA immunoprecipitation; MSP, Nested-methylation-specific PCR. 
These inner ear stem/progenitor cells have shown the capability to differentiate into cells expressing hair cell genes Myo7a and Pou4f3 (Kelley, 2006; Savary et al., 2007; Koehler and Hashino, 2014). Our previous study has demonstrated that adult mouse utricle sensory epithelial cells are able to become prosensorylike cells (MUCs; Zhang and Hu, 2012), which express the genes that are shown in hair cell progenitor cells (Kelley, 2006), suggesting that MUCs may be a valuable cell source to study mammalian hair cell regeneration. For the purpose of future clinical applications to replace human sensory hair cells, it is ideal to guide stem cells to become sensory hair cells without changing DNA sequence. However, it remains unclear how to efficiently achieve this research aim and the mechanism critical for cell differentiation is still obscure.

DNA methylation/demethylation is one of the major epigenetic modifications to regulate gene expression without changing DNA sequence (Jones and Takai, 2001; Jaenisch and Bird, 2003). DNA methylation is a process of adding methyl group to 5-cytosine catalyzed by DNA methyltransferase (DNMT). In mammals, DNMT family has three major members including DNMT1, DNMT3a, and DNMT3b. DNMT1 is responsible for maintenance of methylation pattern through DNA replication, whereas DNMT3a and DNMT3b take charge of the de novo DNA methylation. DNA methylation by addition of methyl group to the promoter sequence leads to gene silence, whereas DNA demethylation by removing methyl group from the promoter region of the silenced gene stimulates gene expression (Sanz et al., 2010; Guo et al., 2014). For example, DNA methylation inhibits gene expression in a hematopoietic stem cell line OCI-AML3 by adding methyl groups to the promoter region and transcription start site. However, DNA demethylation of OCI-AML3 activates gene expression by decreasing the genomic methylation level (Lund et al., 2014). It has been reported that DNA demethylation is involved in lineage specification in mouse neural stem cells (Wheldon et al., 2014) and reprogramming of mouse somatic cells into pluripotent stem cells (Chen et al., 2015). These pioneer studies suggest that DNA demethylation plays a critical role in stem cell fate determination. However, previous reports have only studied the relationship between DNA demethylation and gene expression. It is still unclear whether DNA demethylation is able to stimulate the differentiation of stem cells, trigger the expression of differentiation proteins and generate functional differentiated cells.

In our previous study, we treated MUCs with the DNMT inhibitor 5-aza-2'-deoxycytidine (5-aza-CdR) and found that the genomic methylation level was significantly decreased (Zhou and Hu, 2015). 5-aza-CdR treated MUCs increased expression of epithelial genes, hair cell genes, and prosensory genes. However, 5-aza-CdR did not significantly affect the protein expression of epithelial sensory hair cell markers E-cadherin, Cytokeratin, Myosin VI, and Myosin VIIa, which may be a possible explanation for incomplete hair cell differentiation. Moreover, expression of DNMT1 gene was not significantly changed after 5-aza-CdR treatment. Therefore, additional study and alternative approaches are necessary to guide MUCs to undergo a more complete hair cell differentiation at the protein expression and functional levels.

It has been reported that 5 -aza-CdR can only incorporate into DNA and irreversibly binds to DNMT to reduce the addition of methyl groups to DNA (Liyanage et al., 2013; Hackanson and Daskalakis, 2014). There is no evidence showing that 5-aza-CdR has direct effects on protein expression. 5-azacytidine (5-aza) is another DNA methyltransferase inhibitor, which is able to incorporate into both genomic DNA and RNA (Aimiuwu et al., 2012; Borodovsky et al., 2013). The incorporation of 5-aza into DNA shares the similar mechanism of 5-aza-CdR incorporation into DNA. However, 5-aza is primarily incorporated into RNA rather than DNA, by which triggers polyribosome disassembly and defective methylation of transfer RNA, and repress DNMT protein production (Schneider-Stock et al., 2005; Chen et al., 2013). 5-aza has been used to regulate expression of tumor suppressor gene in myelodysplastic syndromes (MDS) and acute myeloid leukemia (AML; Kimura et al., 2012; Orskov et al., 2015), and it has been applied to stem cell research (Rosca and Burlacu, 2011). For instance, 5-aza causes considerable demethylation in the promoter region of osteogenic specific genes, and stimulates mouse bone marrow derived mesenchymal stem cells to differentiate into osteoblasts (Zhou et al., 2009). Additionally, 5-aza regulates expression of bone morphogenetic protein-4 (BMP4) in mouse pluripotent stem cells, which induces adipocyte lineage differentiation (Bowers et al., 2006). These studies suggest that 5-aza may affect the methylation level of stem/progenitor cells to influence stem cell fate determination.

DNA demethylating agents including the DNMT inhibitor 5-aza work best on proliferating cells; therefore, we apply 5aza to proliferating cell lines such as MUCs in this study. We aimed to investigate whether 5-aza would be able to affect genomic methylation level to stimulate the expression of sensory hair cell genes and proteins. Moreover, we planned to explore the molecular mechanism underlying 5-aza-caused hair cell differentiation using genomic methylation quantification, nested methylation specific PCR (nested-MSP) targeting the promoter region of studied genes, methylated DNA immunoprecipitation (MeDIP), and DNMT activity assays.

\section{MATERIALS AND METHODS Cell Culture and DNA Demethylation Treatment}

Mouse utricle sensory epithelia-derived progenitor cell lines (MUC), which have been established in our previous study (Zhang and $\mathrm{Hu}, 2012$ ), were used in this study. MUCs were cultured in DMEM/F12 GlutaMAX ${ }^{\mathrm{TM}}$ with $10 \%$ fetal bovine serum (FBS, all from Invitrogen) in an incubator supplied with $5 \% \mathrm{CO}_{2}$ at $37^{\circ} \mathrm{C}$ (Zhang and $\mathrm{Hu}, 2012$ ). 5-azacytidine (5-aza, Sigma) was applied to MUC when the cell confluence reached 40-50\%. MUCs in the control group were cultured in the culture medium in the absence of 5-aza. Control and treated MUCs were observed daily using phase contrast microscopy and images were captured using a digital camera. MUCs were treated with 
5-aza for 5 days, and MUCs were passaged when cell confluence reached $70-80 \%$.

\section{Viability Assay}

To test the cytotoxicity of 5-aza, MUCs were exposed to 20, $40,80,160$, and $320 \mu \mathrm{M}$ of 5 -aza for $48 \mathrm{~h}$. In the control group, MUCs were kept in the medium containing vehicle (DMEM/F12). After 48 h of 5-aza treatment, $2 \mu \mathrm{M}$ calcein AM, and $0.3 \mu \mathrm{g} / \mathrm{ml}$ propidium iodide (PI, both from Invitrogen) were added to culture medium for $30 \mathrm{~min}$, followed by Hoechst 33,342 (10 $\mu \mathrm{g} / \mathrm{ml}$, Invitrogen) staining to label nuclei. MUCs were observed by epifluorescence microscopy with a cooled CCD camera ( $n=5$ /group). One-way analysis of variance (ANOVA) and Tukey's post-hoc test were used for analysis and $P<0.05$ was determined as the criterion of statistical significance in this study.

\section{RNA Extraction, Reverse Transcription PCR (RT-PCR), and Real Time Quantitative RT-PCR (Quantitative PCR)}

After 5 days of 5-aza treatment, total RNA was extracted from the control and treated MUCs with an RNeasy Mini Kit (Qiagen), followed by cDNA conversion using a QuantiTect Reverse Transcription Kit (Qiagen) according to manufacturers' protocols. A thermal cycler (Eppendorf) was used for RT-PCR with GoTaq ${ }^{\circledR}$ Green Master Mix (Promega) and primers in Table 1. PCR products were electrophoresed and imaged using a ChemiDoc-It ${ }^{\circledR} 2$ imaging system (UVP).

TABLE 1 | Primers used in RT-PCR, quantitative PCR, Nested-MSP and MeDIP-quantitative PCR.

\begin{tabular}{|c|c|c|c|}
\hline Gene & Forward: $5^{\prime}-3^{\prime}$ & Reverse: $5^{\prime}-3^{\prime}$ & Product length (bp) \\
\hline Gapdh & GGCCGCATCTTCTTGTGCAGT & TGCAAATGGCAGCCCTGGTGA & 111 \\
\hline Cah1 & ATTCAAAGTGGCGACAGACGGC & ACCTGGGTACACGCTGGGAAACAT & 223 \\
\hline Krt8 & CAAGGTGGAACTAGAGTCCCG & CTCGTACTGGGCACGAACTTC & 187 \\
\hline Snai1 & ATGCACATCCGAAGCCACACG & TGGAGCAAGGACATGCGGGAGAA & 245 \\
\hline Snai2 & CATCCTTGGGGCGTGTAAGTC & GCCCAGAGAACGTAGAATAGGTC & 186 \\
\hline Zeb1 & ACTGCAAGAAACGGTTTTCCC & GGCGAGGAACACTGAGATGT & 127 \\
\hline Zeb2 & CCACGCAGTGAGCATCGAA & CAGGTGGCAGGTCATTTCTT & 131 \\
\hline Vim & AAGCCGAAAGCACCCTGCAGTCAT & AGGTCAGGCTTGGAAACGTCCACA & 202 \\
\hline Fn1 & GTGACACTTATGAGCGCCCTA & CCACTTGTCGCCAATCTTGTA & 137 \\
\hline Cdh2 & ATGCCCTGAATGGAATGCTGCGGT & GCTGTGGCTGTGTTTGAAAGGCCA & 211 \\
\hline Bmp4 & CATGAGGGATCTITACCGGCTC & TCTCCAGATGTTCTTCGTGATGG & 140 \\
\hline$P 27^{k i p 1}$ & GCGGTGCCTTTAATTGGGTC & TTCGGGGAACCGTCTGAAAC & 197 \\
\hline Prox1 & TGGAGAAGTATGCGCGTCAA & CTGCGCAACTTCCAGGAATC & 155 \\
\hline Lfng & GCCGTCAAGACCACCAGAAAG & GGTCATACTCCACAGCCATCTT & 208 \\
\hline Sox2 & GCGGAGTGGAAACTITGTCC & CGGGAAGCGTGTACTTATCCTT & 157 \\
\hline$D / x 5$ & CACCACCCGTCTCAGGAATC & GCTTGCCATAAGAAGCAGAGG & 125 \\
\hline Notch1 & GCGTCACTTGGCAGCCTCAA & CACCCCACAGCCCACAAAGA & 144 \\
\hline Hes1 & AGCACAGAAAGTCATCAAAGCC & ATGTCTGCCTTCTCTAGCTTGG & 142 \\
\hline Hes5 & AGTCCCAAGGAGAAAAACCGA & GCTGTGTTCAGGTAGCTGAC & 183 \\
\hline $\mid s / 1$ & ATGATGGTGGTTACAGGCTAAC & TCGATGCTACTTCACTGCCAG & 174 \\
\hline Jag1 & CCTCGGGTCAGTTTGAGCTG & CCTTGAGGCACACTTTGAAGTA & 150 \\
\hline Numb & CTTCCCAGTTAAGATCCTCGGC & CCCGTTGTTCCAAAGAAGCCT & 126 \\
\hline Atoh1 & CCCGTCCTTCAACAACGACAAG & AGGTGATGGTGGTCATIITTGC & 156 \\
\hline Myo7a & GCACTTCATCATCGGCAACGGCAT & GCTGCTCTTGGATGGGTTGTGTGT & 100 \\
\hline Myo6 & GGCATCGTCCCAAGAGATTITC & CCACAATGTCAAAGTTCGGTACA & 150 \\
\hline Espn & CTGCCTGGAGACGAGACATT & GCAGCTTCTCCGACTGTTCT & 123 \\
\hline Pou4f3 & CGCACAACAACATGATCGCT & TTCTCGGATGAAGGACGTGG & 199 \\
\hline Methylated Cdh1 & GTITTAGTTAATTAGCGGCGTC & ACACTAAACTCGAATACGATCGAA & 175 \\
\hline Unmethylated Cdh1 & GTITTAGTTAATTAGTGGTGTTGG & САСТАAАСТСАААТАСАAТСAАА & 174 \\
\hline Methylated Atoh1 & TATITGTAGGCGAGAGATIIITC & АСТCACССТАACTATCAACCTCGT & 197 \\
\hline Unmethylated Atoh1 & ПITGTAGGTGAGAGATIIITGT & ААСТСАСССТААСТАТСААССТСАТ & 196 \\
\hline Methylated Pou4f3 & GCGGTTCGTITGTTITC & GTTCATAACCATCATCTTCGAA & 263 \\
\hline Unmethylated Pou4f3 & GATTGTGGTTTGTITGTIITT & AАСАТTCATAACCATCATCTTCAAA & 271 \\
\hline MeDIP Cdh1 & TTAGTTAGTAAAGGTTAATGGCGG & АAACTTATTCATCATCTAAATTTCCGT & 268 \\
\hline MeDIP Atoh1 & TIIITIGATTGGGTAGATACGC & CTCCGATTACTAAAAACGCTACG & 117 \\
\hline MeDIP Pou4f3 & GCGGTTCGTITGTाTाC & GTTCATAACCATCATCTTCGAA & 263 \\
\hline
\end{tabular}


Quantitative PCR was performed by Bio-Rad CFX system with SsoAdvanced $^{\mathrm{TM}}$ SYBR $^{\circledR}$ Green Supermix (Bio-rad) $(n=3)$. The melting temperature and efficiency of primers have been determined in a previous study (Zhou and $\mathrm{Hu}, 2015$ ). The mean quantification cycle (Cq) was calculated by Bio-Rad CFX Manager software in a regression mode and studied genes with Cq value $>40$ was believed no expression and excluded from statistical analysis. The $\mathrm{Cq}$ values of the internal control gene Gapdh in the control and treated groups that had been calibrated within one cycle were used as calibrator references for analysis.

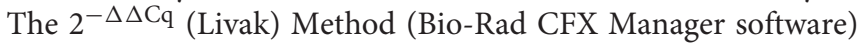
was used to quantify the fold change of studied genes. In quantitative analysis, relative mRNA expression change $\geq 2$-fold was considered to be biologically important and qualified for statistical analysis, and a two-tailed Student's $t$-test was used for statistical analysis.

\section{Genomic DNA Extraction, Bisulfite Conversion Reactions, and Nested-Methylation-Specific PCR (Nested-MSP)}

Genomic DNA (gDNA) was extracted from MUCs from the control and treatment groups using a Flexi DNA Kit (Qiagen), followed by a bisulfite conversion reaction using an EpiTect Bisulfite Conversion Kit (Qiagen) according to the manufacturer's protocol. Nested-MSP was used to detect the methylation pattern of studied genes with a Qiagen MSP Kit $(n=3)$. The primers targeting the CpG islands of promoter regions of studied genes for nested-MSP were included in Table 1. The products of nested-MSP were analyzed by electrophoresis and ChemiDoc-It ${ }^{\circledR} 2$ imaging system. To compare the methylation level of studied genes, expression of unmethylated studied gene was normalized in the control and treated MUCs.

\section{Methylated DNA Immunoprecipitation (MeDIP) and Quantitative PCR}

Before DNA shearing, gDNA of both control and treated MUCs were diluted to a final concentration of $100 \mu \mathrm{g} / \mathrm{ml}$. Digital sonifier 250 (Branson) was used to shear the gDNA by 5 pulses of sonication at 205 amplitude for $10 \mathrm{~s}$, followed by immunoprecipitation using an EpiQuik ${ }^{\mathrm{TM}}$ Methylated DNA Immunoprecipitation Kit (Epigenetek) according to the manufacturer's protocol. The same amount of gDNA fragments from the control and treatment groups was added to the immunoprecipitation reaction. Quantitative PCR was used to quantitatively evaluate the amount of methylated gene using the same amount of MeDIP product templates of the control and treatment MUCs $(n=3)$. The primers targeting the CpG islands of promotor regions of studied genes for MeDIP quantitative PCR were shown in Table 1. Quantitative amount of methylated gene was described by the mean quantification cycle $(\mathrm{Cq})$, which was calculated by Bio-Rad CFX Manager software. In this study, the mean $\mathrm{Cq}$ value change $\geq 1$ cycle (which means at least two-fold expression changes) was considered to be of biomedical importance. The fold change of studied genes $(\Delta \Delta \mathrm{Cq})$ was calculated using the $2^{-\Delta \Delta \mathrm{Cq}}$ (Livak) Method
(Bio-Rad CFX Manager software). A two-tailed Student's $t$-test was used to compare the mean $\mathrm{Cq}$ values of studied genes between the control and treatment groups. Cq values $>40$ were not considered to have significant gene expression thus excluded from statistical analysis.

\section{Immunofluorescence}

After 5 days of 5-aza treatment, control and treated MUCs were fixed in $4 \%$ paraformaldehyde for $10 \mathrm{~min}$ at room temperature, followed by incubation in PBS containing 5\% donkey serum (Jackson Immunoresearch), and $0.2 \%$ Triton X-100 (Sigma) for $20 \mathrm{~min}$. Primary antibodies included epithelial markers anti-E-cadherin (1:200; Santa Cruz) and anti-pan-cytokeratin 26 (PCK26; 1:100; Sigma), and hair cell markers anti-Myosin VI (Myo6; 1:200; Sigma), anti-Myosin VIIa (Myo7a; 1:200; DSHB), anti-Math1 (Atoh1; 1:200; DSHB), anti-Pou4f3 (1:200; Sigma), anti-Espin (1:100; a gift from Dr. James Richard Bartles, Northwestern University), anti-DNMT1 (1:100; Epigentek) and anti-PCNA (1:100; Abcam). Secondary antibodies were Dylight488-, Dylight-549,- and Dylight-649-conjugated antibodies, with a universal nuclear marker, $4^{\prime}, 6$-diamidino-2-phenylindole (DAPI, all from Jackson Immunoresearch). MUC samples were incubated with primary antibodies overnight at $4{ }^{\circ} \mathrm{C}$, followed by secondary antibodies incubation for $2-3 \mathrm{~h}$ at room temperature. MUCs were observed using a Leica epifluorescence microscope and images were captured using a QImaging monochrome cool CCD camera.

\section{Nuclear Extraction and Western Blotting}

The nuclear extracts from the control and treated MUCs were harvested using a Chemicon Nuclear Extraction Kit (Millipore) according to the manufacturer's protocol. Western blotting was used to study the protein expression in the control and treated MUCs $(n=3)$. Antibodies used in western blotting included monoclonal goat anti-E-cadherin (E-cad, 1:100; Santa Cruz), polyclonal rabbit anti-Myosin VI (1:100; Sigma), monoclonal mouse anti-Myosin VIIa (1:100; DSHB), polyclonal rabbit anti-Pou4f3 (1:200; Sigma), monoclonal mouse anti-DNMT1 (1:100; Epigentek), and mouse anti-GAPDH (1:200; Thermo Scientific). Secondary antibodies included donkey anti-goat HRP-conjugated, donkey anti-rabbit HRP-conjugated, donkey anti-mouse HRP-conjugated antibodies, and HRP standard protein (all from Bio-Rad). Clarity ${ }^{\mathrm{TM}}$ ECL Western Blotting Substrate (Bio-Rad) was applied to blotting membranes, and images were captured by a ChemiDoc-It ${ }^{\circledR} 2$ imaging system. To quantify protein expression changes, Image (NIH) was used to measure the band density of studied proteins. The protein band density of control MUCs was normalized to 1, and the protein density of treated MUCs was determined by its relative intensity to that of control MUCs.

\section{Genomic Methylated DNA Quantification}

Genomic methylated DNA was examined using a MethylFlash Methylated DNA Quantification Kit (Epigentek). The positive control of methylated DNA was artificially synthesized and provided with the kit by the manufacturer, in which $50 \%$ DNA has been methylated at 5-cytosine. A standard curve was generated by diluting the positive control to a series 
of concentrations at $0,0.5,1,2,5$, and $10 \mu \mathrm{g} / \mathrm{ml}$ following the manufacturer's protocol. The relative fluorescence unite (RFU) was read at $530_{\mathrm{EX}} / 590_{\mathrm{EM}} \mathrm{nm}$ using a Gemini $\mathrm{EM}$ fluorescence microplate reader (Molecular Devices). The genomic methylation level was quantified by the percentage of 5-methylcytosin (5-mC\%), which was determined as

(sample RFU-negative control RFU) $\div$ amount of input sample DNA (ng)

(positive control RFU-negative control RFU) $\times 2 \div$ amount of input positive control (ng)

$\times 100 \%(n=4)$. The genomic methylation inhibition was calculated as: $\frac{5-\mathrm{mC} \%(\text { experiment })-5-\mathrm{mC} \%(\text { control })}{5-\mathrm{mC} \%(\text { experiment })} \times 100 \%$. A two-tailed Student's $t$-test was used to compare the $5-\mathrm{mC} \%$ of the control and treatment groups.

\section{DNMT Activity Assay}

DNMT activity was estimated in the nuclear extracts of the control and treatment group using an EpiQuik DNMT Activity/Inhibition Assay Ultra Kit-Fluorometric (Epigentek) according to the manufacturer's protocol. Gemini EM fluorescence microplate reader was used to read the relative fluorescence unit (RFU) at $530 \mathrm{EX} / 590_{\mathrm{EM}}$ $\mathrm{nm}(n=4)$. DNMT activity $(\mathrm{RFU} / \mathrm{h} / \mu \mathrm{g})$ was determined as: (Sample-Blank RFU)

Protein amount $(\mu g) \times$ Reaction time $(\mathrm{h})$. The DNMT inhibition was calculated as: $\frac{\text { Treated sample RFU-Blank RFU }}{\text { Control sample RFU-Blank RFU }} \times 100 \%$.

\section{Mechanotransduction Channel Permeation Assay}

Functional sensory hair cells usually possess potent mechanosensory transduction channels to convert mechanical movements into cellular activities. A styryl pyridinium dye N-(3-triethylammoniumpropyl)-4-[4-(dibutylamino)styryl] pyridiniumdibromide, FM1-43 has been used to evaluate functional mechanosensory transduction channels in development and stem cell regeneration (Geleoc and Holt, 2003; Hu and Corwin, 2007). In this study, FM1-43 (Invitrogen) was used as a probe to investigate the existence of mechanotransduction channels. In an initial optical assay for mechanotransduction channel function, the control and treated MUCs were incubated in DMEM/F12 containing $5 \mu \mathrm{M}$ FM1-43 for $5-30 \mathrm{~s}$ at room temperature and rinsed by DMEM/F12 for 3 times $(n=5)$. Samples were immediately examined under a Leica epifluorescence microscope and imaged using a QImaging monochrome cool CCD camera. In quantitative study, MUCs showing FM1-43 label around nuclei were quantified for cell counting $(n=5)$.

\section{RESULTS}

\section{Viability of MUCs Following 5-Aza Treatment}

Calcein AM, propidium iodide (PI), and Hoechst 33342 were used to determine the viability of MUCs. After treatment of 5-azacytidine (5-aza) for $48 \mathrm{~h}$, viable MUCs were stained with calcein AM showing green (Figure 1A; $n=5$ ). Approximately $81.75 \pm 1.72 \%, 74.86 \pm 3.48 \%, 73.52 \pm 2.50 \%, 68.21 \pm 4.41 \%$, $62.48 \pm 2.19 \%$, and $56.38 \pm 4.26 \%$ MUCs were labeled by calcein AM when exposed to 0 (control), 20,40,80, 160, and 320 $\mu \mathrm{M} 5$-aza respectively (Figure $1 \mathbf{B} ; n=5$ ). One-way analysis of variance (ANOVA) showed significant difference among these groups $(P<0.05)$. Comparing with control MUCs, Tukey posthoc test indicated that 80,160 , and $320 \mu \mathrm{M}$ 5-aza treatments caused a significant reduction in the number of viable MUCs $(P$ $<0.05$ ), whereas 20 and $40 \mu \mathrm{M} 5$-aza did not have significant effects $(P>0.05)$. The dead MUCs were labeled by PI showing red (Figure 1A). Quantitative analysis showed that $5.56 \pm 1.52 \%$, $11.23 \pm 2.53 \%, 16.89 \pm 1.01 \%, 23.27 \pm 2.89 \%, 29.18 \pm 3.07 \%$, and $35.08 \pm 4.57 \%$ MUCs were stained by PI in 0 (control), 20 , $40,80,160$, and $320 \mu \mathrm{M}$ 5-aza, respectively (Figure 1B), which was significantly different $(P<0.05$, ANOVA). Tukey post-hoc test suggested a significantly increased number of dead MUCs in 80,160 , and $320 \mu \mathrm{M} 5$-aza groups $(P<0.05)$. Neither 20 nor 40 $\mu \mathrm{M} 5$-aza caused obvious cell death $(P>0.05)$. Therefore, $40 \mu \mathrm{M}$ 5 -aza was selected for further studies.

\section{Expression of Prosensory Genes Following 5-Aza Treatment}

Reverse transcription PCR (RT-PCR) showed that expression of some prosensory genes including Sox2, Bmp4, Lfng, Proxl, and $P 27^{k i p 1}$ was significantly higher in the treatment group than those in the control group (Figure 2A). Quantitative PCR showed 3.53 $\pm 0.11,4.49 \pm 0.64,10.86 \pm 0.27,7.17 \pm 0.17$, and $5.36 \pm 0.17$ fold of up-regulation of Bmp4, Sox2, Prox1, Lfng and P27 $7^{k i p 1}$ respectively, which was statistically significant (Figure $2 \mathrm{D} ; P<$ 0.05 , Student's $t$-test). Other studied prosensory genes did not show significant expression changes ( $\leq 2$-fold), including Jag1 (1.22 \pm 0.04 fold), Hes 1 ( $1.18 \pm 0.04$ fold $),$ Dlx 5 (0.55 \pm 0.02 fold), and $I s l 1$ ( $1.03 \pm 0.03$ fold).

\section{Expression of Sensory Hair Cell Markers and Differentiation of Functional Hair Cell-Like Cells}

In response to $40 \mu \mathrm{M} 5$-aza treatment for 5 days, expression of epithelial genes $\mathrm{Cdh} 1$ and $\mathrm{Krt8}$ was increased comparing with control MUCs (Figure 2B). Quantitative PCR showed that $C d h 1$ and $K r t 8$ had $2.50 \pm 0.35$ and $5.50 \pm 0.45$ fold of upregulation after treatment respectively (Figure 2E). To study whether treated MUCs differentiated into hair cells, expression of hair cell genes was investigated using RT-PCR and quantitative PCR. After treatment, RT-PCR suggested increased expression of hair cell genes including Atoh1, Myo7a, Myo6, Espn, and Pou4f3 (Figure 2C). In quantitative PCR, normalized relative expression of Atoh1, Myo7a, Myo6, Espn, and Pou4f3 was $\sim 3.74 \pm 1.27$, $3.10 \pm 0.19,2.89 \pm 0.07,4.14 \pm 0.07,274.42 \pm 45.49$ fold higher than those of control MUCs respectively (Figure 2F). Student's $t$-test indicated significant difference between the control and treatment groups $(P<0.05)$.

Immunofluorescence indicated that control MUCs did not exhibit expression of E-cadherin (E-cad, encoded by $C d h 1$ ), pancytokeratin 26 (PCK26, encoded by Krts including Krt8), Math1 

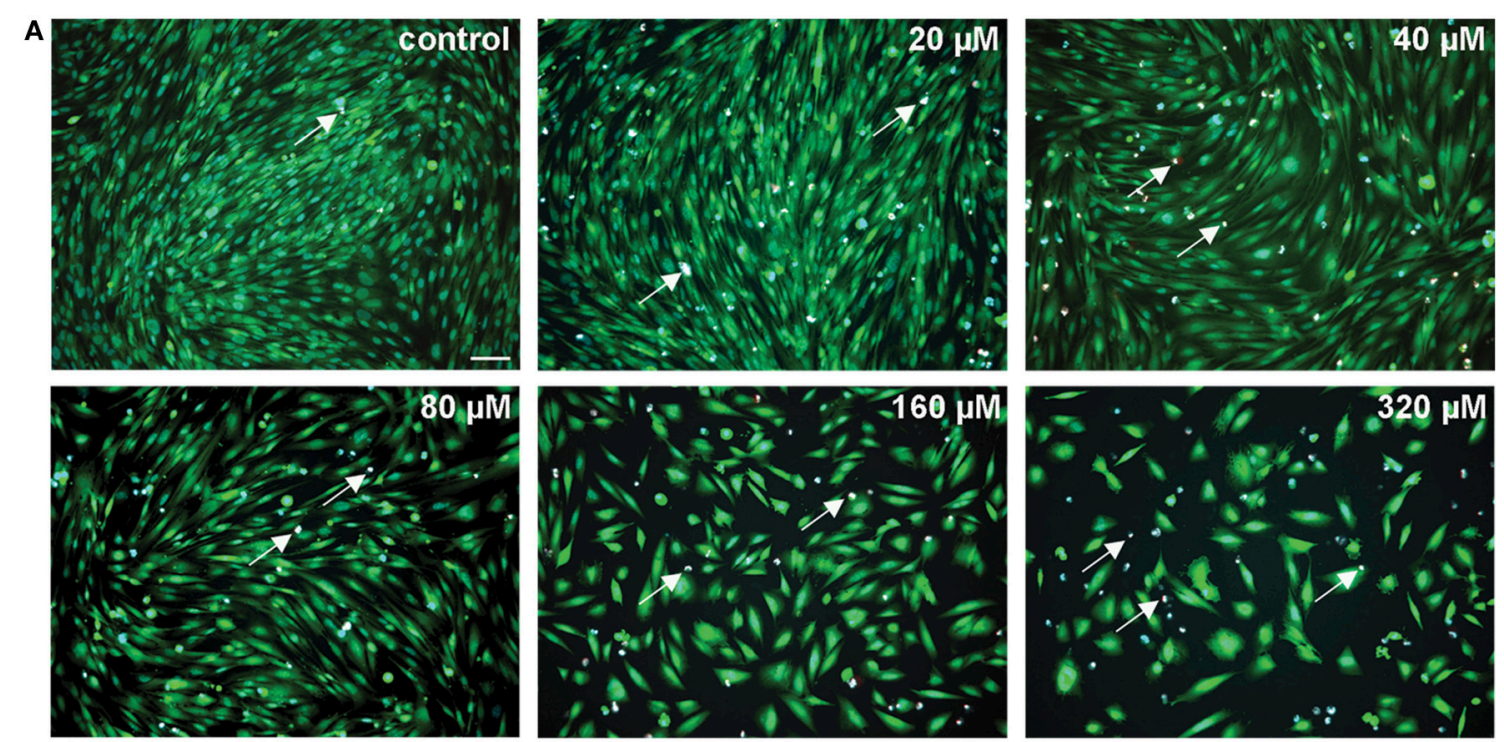

B
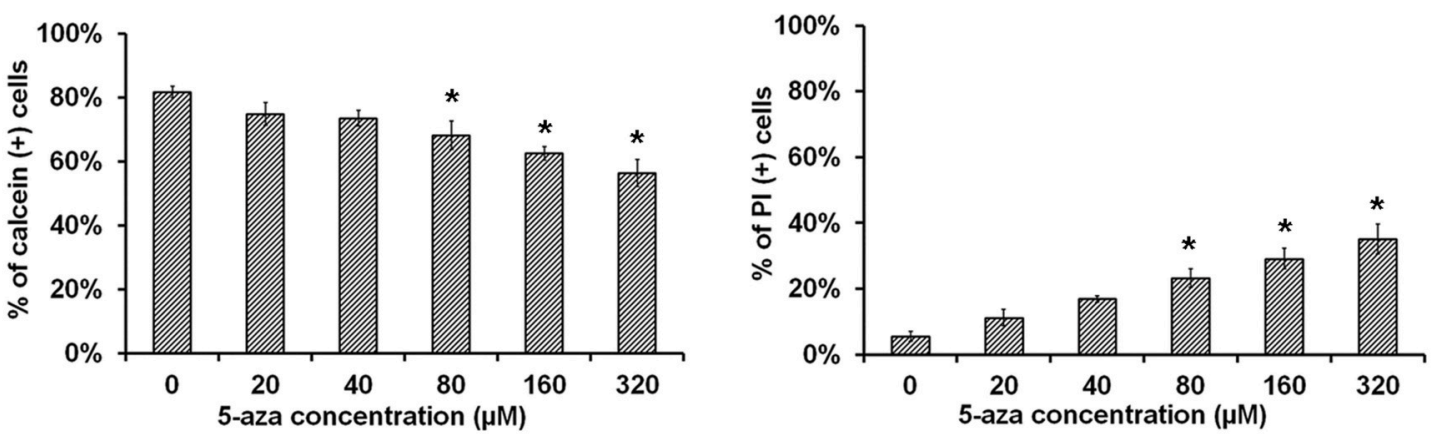

FIGURE 1 | Viability of MUCs following 5-aza treatment. (A) Calcein and PI were used to determine the viability of MUCs treated with $0,20,40,80,160$, and 320

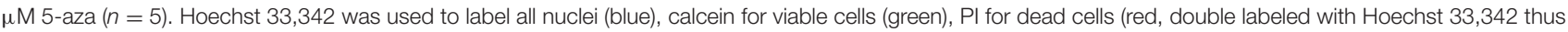
showing in pink, arrows). Scale bar, $100 \mu \mathrm{m}$. (B) The percentage of viable cells decreased with the 5-aza concentration, whereas percentage of dead cells increased, which was significantly different $(P<0.05$ ANOVA). Tukey post-hoc test suggested that 20-40 $\mu \mathrm{M}$ 5-aza did not cause obvious cell death $(P>0.05)$.

(encoded by Atoh1), Myosin VI, or Pou4f3, but had weak Myosin VIIa expression. After treatment, immunofluorescence showed that treated MUCs significantly increased protein expression of these sensory hair cell markers (Figure 3A). Additionally, western blotting revealed remarkably increased expression of E-cadherin, Myosin VIIa, Myosin VI, and Pou4f3 in treated MUCs (Figure 3B). To quantify protein expression changes, we measured protein band density using ImageJ, with protein band density of control MUCs normalized to 1 . We found that the relative protein densities in treated MUCs were GAPDH $97.71 \pm 2.33 \%$, E-cadherin $155.71 \pm 9.86 \%$, Myosin VIIa 238.41 $\pm 6.42 \%$, Myosin VI $176.33 \pm 12.96 \%$, and Pou4f3 $157.51 \pm$ $7.06 \%$ (Figure 3B). These protein studies indicated that 5 -aza was able to stimulate MUCs to increase protein expression of hair cell markers. To further ascertain sensory hair cell generation, treated MUCs were double labeled by epithelial hair cell markers, including Myosin VIIa + Myosin VI and Myosin VIIa + Pou4f3 (Figure 3C). Quantitative study showed that $29.04 \pm 4.65 \%$ of treated MUCs were Myosin VIIa and Myosin VI positive $(n=5)$. Additionally, the hair bundle-like structures were labeled by
anti-Espin antibody (encoded by Espn; Figure 3C). To examine whether hair cell-like cells are newly-generated cells, anti-PCNA antibodies were used to co-label with anti-Myosin VI antibodies and the result indicated that some treated MUCs were both PCNA and Myosin VI positive (Figure 3D), suggesting that hair cell-like cells were newly-generated cells. These results demonstrated that treated MUCs expressed hair cell proteins and the hair bundle specific protein Espin, indicating that 5aza was able to stimulate MUCs to adopt a hair cell-like cell fate.

Because we found expression of hair cell genes and proteins in treated MUCs, we performed a mechanosensory transduction permeation assay to investigate whether treated MUCs possessed mechanosensory transduction channels, which are specifically shown in sensory hair cells. FM1-43 has been reported to be able to fill into the cytoplasm of hair cells with functional mechanosensory transduction channels when hair cells are briefly exposed to this compound (Geleoc and Holt, 2003). Additionally, FM1-43 permeation assay has been used to determine mechanosensory transduction channels in stem cell studies ( $\mathrm{Hu}$ and Corwin, 2007). In 

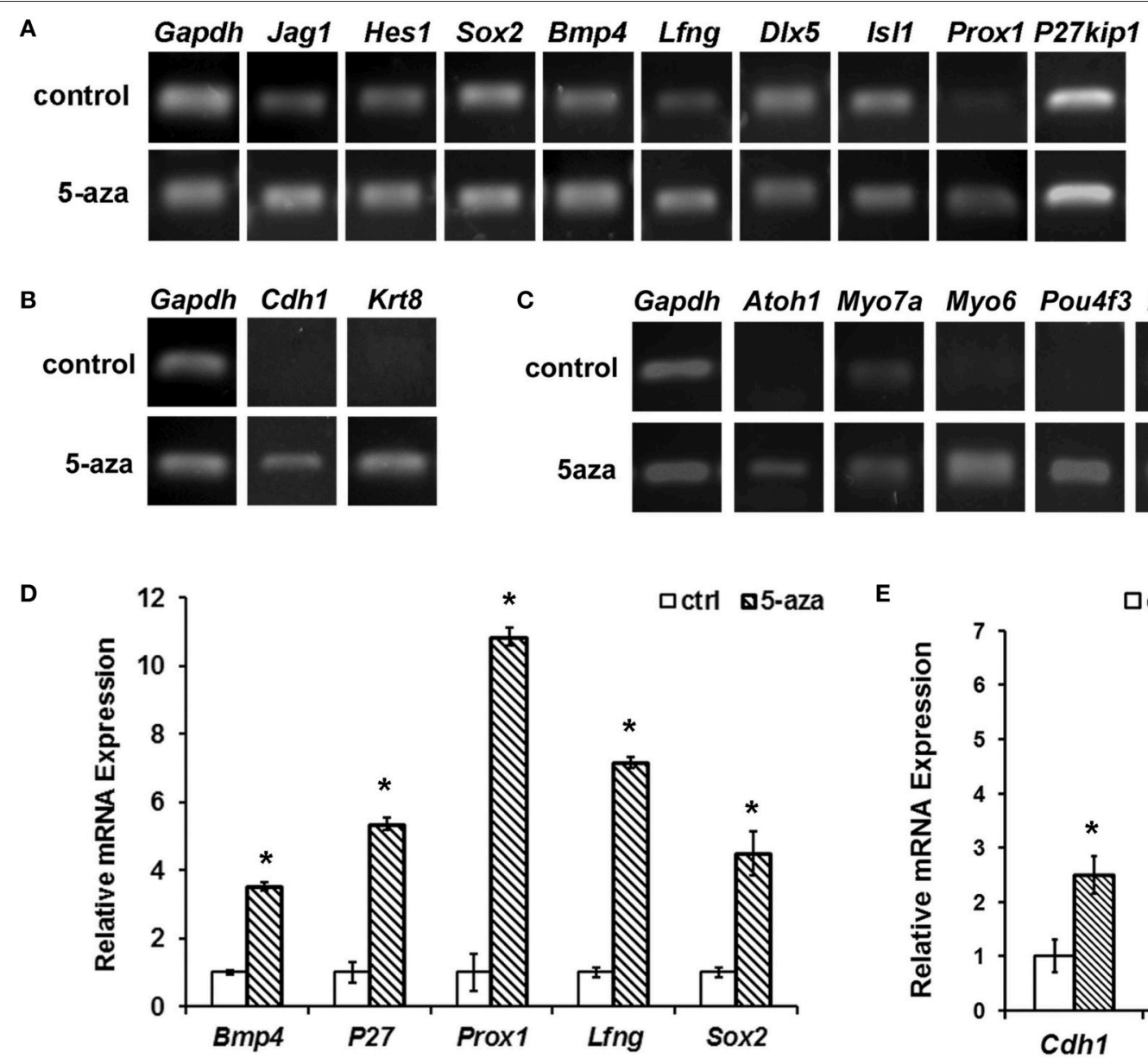

B
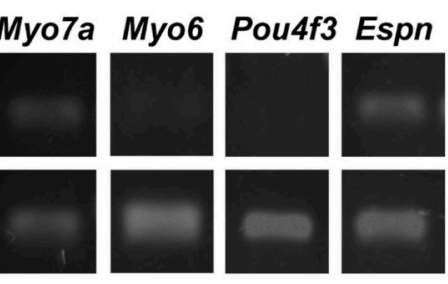

D

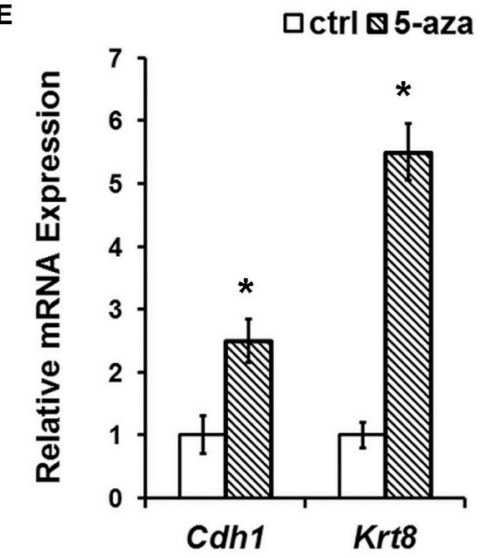

$\mathbf{F}$
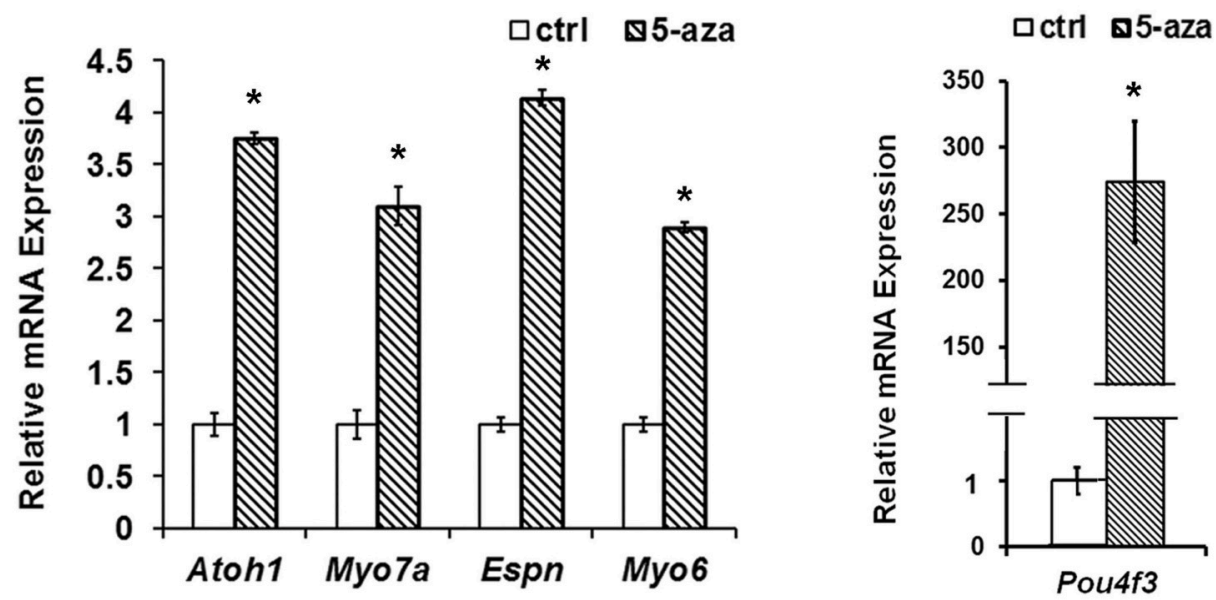

FIGURE 2 | Gene expression changes following 5-aza treatment. (A) Following 5-aza treatment, RT-PCR showed increased expression in Sox2, Bmp4, Lfng, Prox1, and P27 $7^{k i p 1}$, whereas no obvious change in Jag1, Hes1, Is/1, and DIx5. (B) RT-PCR showed that MUCs up-regulated expression of epithelial genes Cdh1 and Krt18 following 5-aza treatment. (C) RT-PCR showed that expression of hair cell genes Atoh1, Myo7a, Myo6, Espn, and Pou4f3 was up-regulated following 5-aza treatment. (D) Quantification PCR showed $\sim 3.53 \pm 0.11,5.36 \pm 0.17,10.86 \pm 0.27,7.17 \pm 0.17$, and $4.49 \pm 0.64$ fold of up-regulation of Bmp4, P27kip1, Prox1, $L$ fng, and Sox2, respectively after 5-aza treatment $(P<0.05$, Student $t$-test; $n=5)$. (E) Quantification PCR showed normalized relative expression of $C d h 1$ and $K r t 18$ of treated MUCs were $2.50 \pm 0.35$ and $5.50 \pm 0.45$ fold higher than those of control MUCs, which is statistically significant $(P<0.05$; Student's $t$-test; $n=5)$. (F) Quantitative study indicated that normalized relative expression values of Atoh1, Myo7a, Myo6, Espn, and Pou4f3 were $\sim 5.74 \pm 1.27,3.10 \pm 0.19,1.89 \pm 0.07$, $4.14 \pm 0.07,274.42 \pm 45.49$ fold higher than those of control MUCs respectively, and statistical analysis showed significant difference $(P<0.05$; Student's $t$-test; $n=5) .{ }^{*}$ Indicates significant difference comparing with the control group. 
A
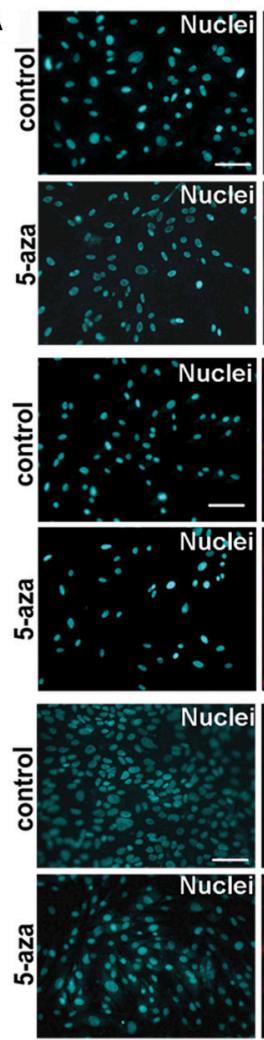

B
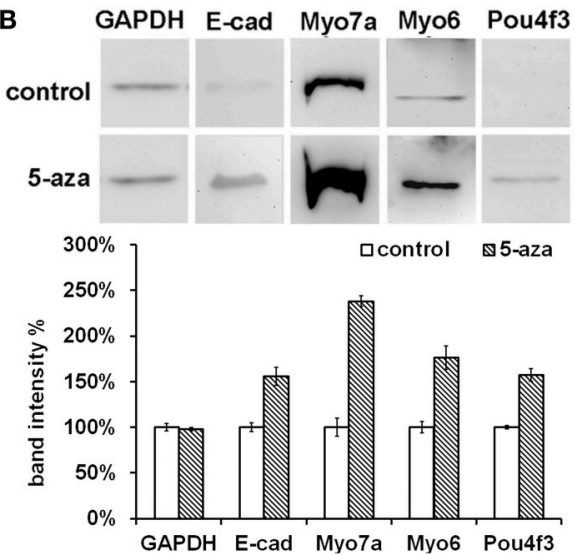

D
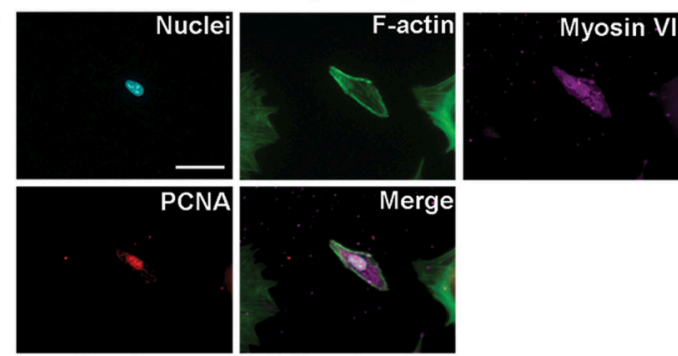

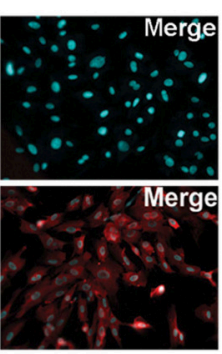

Merge
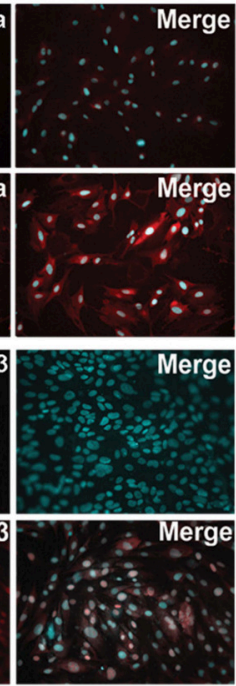

C
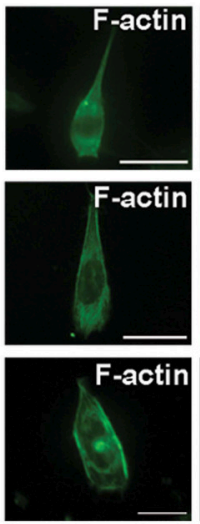

E
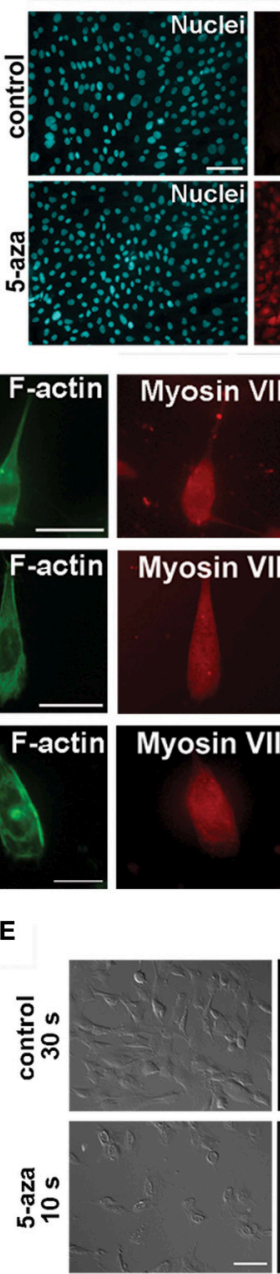
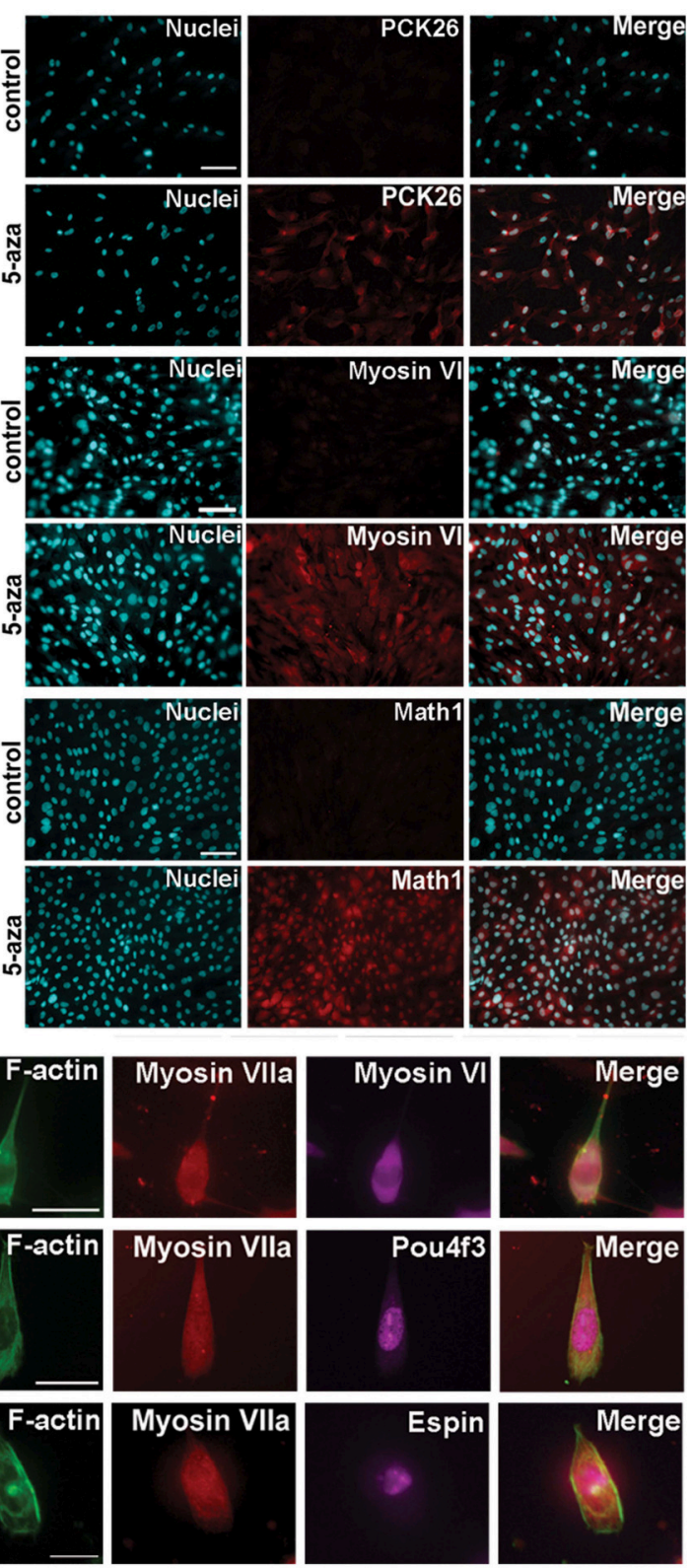

FM1-43
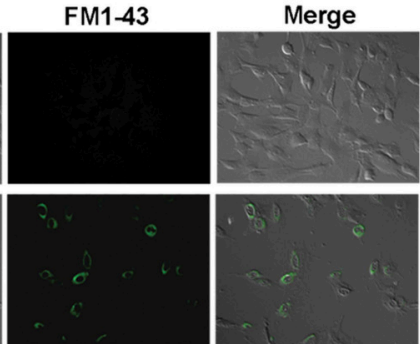

FIGURE 3 | Hair cell protein expression changes following 5-aza treatment. (A) Immunofluorescence showed up-regulated expression of epithelial hair cell markers E-cad, PCK26, Myosin Vlla, Myosin VI, Math1, and Pou4f3 in treated MUCs (Scale bar $100 \mu \mathrm{m}$ ). (B) Western blotting showed significant increased expression of Myosin VIla and Myosin VI, and slightly up-regulation of E-cad and Pou4f3 in treated MUCs. (C) Multiple-labeling immunofluorescence showed that newly-generated hair cell-like cells were double-labeled with Myosin Vlla and Myosin VI, Myosin Vlla and Pou4f3, and Myosin Vlla and Espin (scale bar $50 \mu \mathrm{m}$ ). (D) Hair cell-like cells were PCNA and Myosin VI positive, suggesting that these cells were newly-generated cells (scale bar $50 \mu \mathrm{m}$ ). (E) In initial optical assay using FM1-43 permeation test, control MUCs did not show FM1-43 signal after 30 s incubation. In treated MUCs, 30\% of treated MUCs were filled with FM1-43 when they were exposed to FM1-43 for $10 \mathrm{~s}$ at room temperature (scale bar $100 \mu \mathrm{m}$ ). 
an initial optical assay, we did not observe FM1-43 positive cells in control MUCs after $30 \mathrm{~s}$ of incubation (Figure 3E). In treated MUCs, $\sim 30 \%$ of treated MUCs were filled with FM1-43 when they were exposed to FM1-43 for $10 \mathrm{~s}$ at room temperature (Figure 3E; $n=5$ ). This study revealed that treated MUCs were permeable to FM1-43, suggesting that treated MUCs may possess potential FM1-43-permeation related mechanotransduction channels that are shown in functional sensory hair cells.

\section{Genomic Demethylation, DNMT Expression, and Enzyme Activity Assay}

To study whether 5-aza treatment was related to the generation of hair cell-like cells, we performed a genomic methylated DNA quantification assay to determine the genomic methylation level. The relative quantification of genomic methylated DNA (5-mC\%) of control MUCs was $0.35 \pm 0.04 \%$. After 5 days of 5-aza treatment, the relative $5-\mathrm{mC} \%$ of treated MUCs decreased to $0.25 \pm 0.04 \%$ (Figure 4A). Therefore, the genomic methylation inhibition showed $28.57 \%[(0.35-0.25 \%) / 0.35 \times$ $100 \%$ ] decrease in genomic methylation level in response to 5 -aza treatment. The statistical analysis indicated significant difference of relative $5-\mathrm{mC} \%$ between the control and treatment groups $(P<0.05$, Student's $t$-test $)$.

RT-PCR and quantitative PCR were performed to exam gene expression changes of DNMTs in the control and 5-aza-treated MUCs. After 5-aza treatment, expression of maintenance DNA methylatransferase Dnmt1 and de novo DNA methyltransferase Dnmt3a was not significant changed in RTPCR and quantitative PCR (Figures 4B,D). But expression of de novo DNA methyltransferase Dnmt3b was decreased in RTPCR (Figure 4D), which was confirmed by quantitative PCR $(0.52 \pm 0.01$ fold down-regulation; $P<0.05$, Student's $t$-test; Figure 4B).

To study whether 5-aza affected the activity of DNMT, the DNMT activity assay was applied. The activity of DNMT in the control group was $70.33 \pm 5.24 \mathrm{RFU} / \mathrm{h} / \mu \mathrm{g}$, but it reduced to $59.47 \pm 3.87 \mathrm{RFU} / \mathrm{h} / \mu \mathrm{g}$ after treatment (Figure 4C). The DNMT inhibition assay suggested that there was an approximately $15.37 \pm 0.09 \%$ inhibition effect on DNMT activity after 5aza treatment, which was statistically significant $(P<0.05$, Student's $t$-test).

In the protein assay, both western blotting and immunofluorescence showed down-regulated expression of DNMT1 after treatment (Figures 4E,F). The immunofluorescence study indicated that DNMT1 expression was significantly decreased after treatment. Additionally, expression of DNMT1 was mainly showed in the cytoplasm of control MUCs, whereas its expression translocated to the nuclei of treated MUCs (Figure 4F). Overall, the DNMT1 expression change of treated MUCs showed in the protein level but not in the gene level.

\section{Mechanism of Sensory Hair Cell-Like Cell Differentiation Following 5-Aza Treatment}

It is known that 5 -aza is able to induce genomic demethylation to regulate gene expression in some cell lines (Schneider-Stock et al., 2005; Song et al., 2014); however, it remains unclear whether 5-aza is able to affect the methylation level and plays a role in inducing expression of sensory hair cell genes in tissue specific stem/progenitor cell model MUCs. To address this question and also to further study the relationship between expression of sensory hair cell markers and 5-aza treatment, nested methylation specific PCR (nested-MSP) was performed to examine methylation pattern changes in the promoter region of sensory hair cell genes Atoh1, Pou4f3, and Cdh1 (Figure 4G). The same amount of bisulfite converted gDNA of control and treated MUCs was used as templates in nested-MSP, and the primers were designed to specifically target to the CpG island in the promoter region of studied genes. According to the electrophoresis analysis of nested-MSP, the normalized amount of unmethylated $C d h 1$ of the control and treatment group were similar, whereas the amount of methylated Cdh1 of treated MUCs was slightly lower than that of control MUCs. In the study of nested-MSP of hair cell genes, Atoh1 was highly methylated in control MUCs. After treatment, the amount of methylated Atoh1 was significantly decreased, whereas the amount of unmethylated Atoh1 was remarkably increased. Moreover, treated MUC exhibited an obviously higher expression of unmethylated Atoh1 than methylated Atoh1. Another hair cell gene Pou $4 f 3$ exhibited a significant high amount of methylated expression in control MUCs, whereas the amount of unmethylated Pou $f f 3$ was scarce. After treatment, expression of methylated Pou 43 was completely shut down, whereas the amount of unmethylated Pou $4 \mathrm{f} 3$ was significantly increased. The nested-MSP data suggested that 5-aza caused demethylation of Atoh1 in the promoter region, which may contribute to increased expression of Atoh1 gene.

To further examine the methylation level of studied genes in treated MUCs, methylated DNA immunoprecipitation (MeDIP) and quantitative PCR were performed $(n=3)$. Genomic DNA of the control and treated MUCs was randomly broken into DNA fragments using sonication. The same amount of DNA fragments was added to immunoprecipitation reaction, followed by quantitative PCR to analyze the quantity of methylated $C d h 1$, methylated Atoh1 and methylated Pou 4 f3. The primers were designed to specifically target to the promoter region of studied genes. In control MUCs, the Cq value of methylated Cdh1 was $27.35 \pm 0.01$, whereas it increased to $27.52 \pm 0.46$ after treatment, which was not statistically significant $(P>0.05$, Student $t$-test). The Cq value of methylated Atoh1 in control MUCs was 35.38 \pm 0.38 , which was increased to $37.33 \pm 0.07$ after treatment $(P<0.05$, Student $t$-test). The Cq values of methylated Pou 43 were $23.00 \pm 0.07$ and $24.84 \pm 0.17$ in control and treatment group respectively $(P<0.05$, Student's $t$-test). Compared to control MUCs (normalized to 1), MeDIP quantitative analysis using the $2^{-\Delta \Delta \mathrm{Cq}}$ (Livak) Method showed $0.89 \pm 0.01$ fold of methylated Cdh1, $0.26 \pm 0.07$ fold of methylated Atoh 1 and 0.28 \pm 0.07 fold of methylated Pou $4 \mathrm{f} 3$ in treated MUCs (Figure $4 \mathbf{H}$ ). These studies suggested that decreased amount of methylated Atoh1 and Pou4f3 may lead to up-regulated hair cell gene expression, and that increased expression of hair cell gene Atoh1 and Pou $f f 3$ was likely caused by demethylation of their promoter regions. 


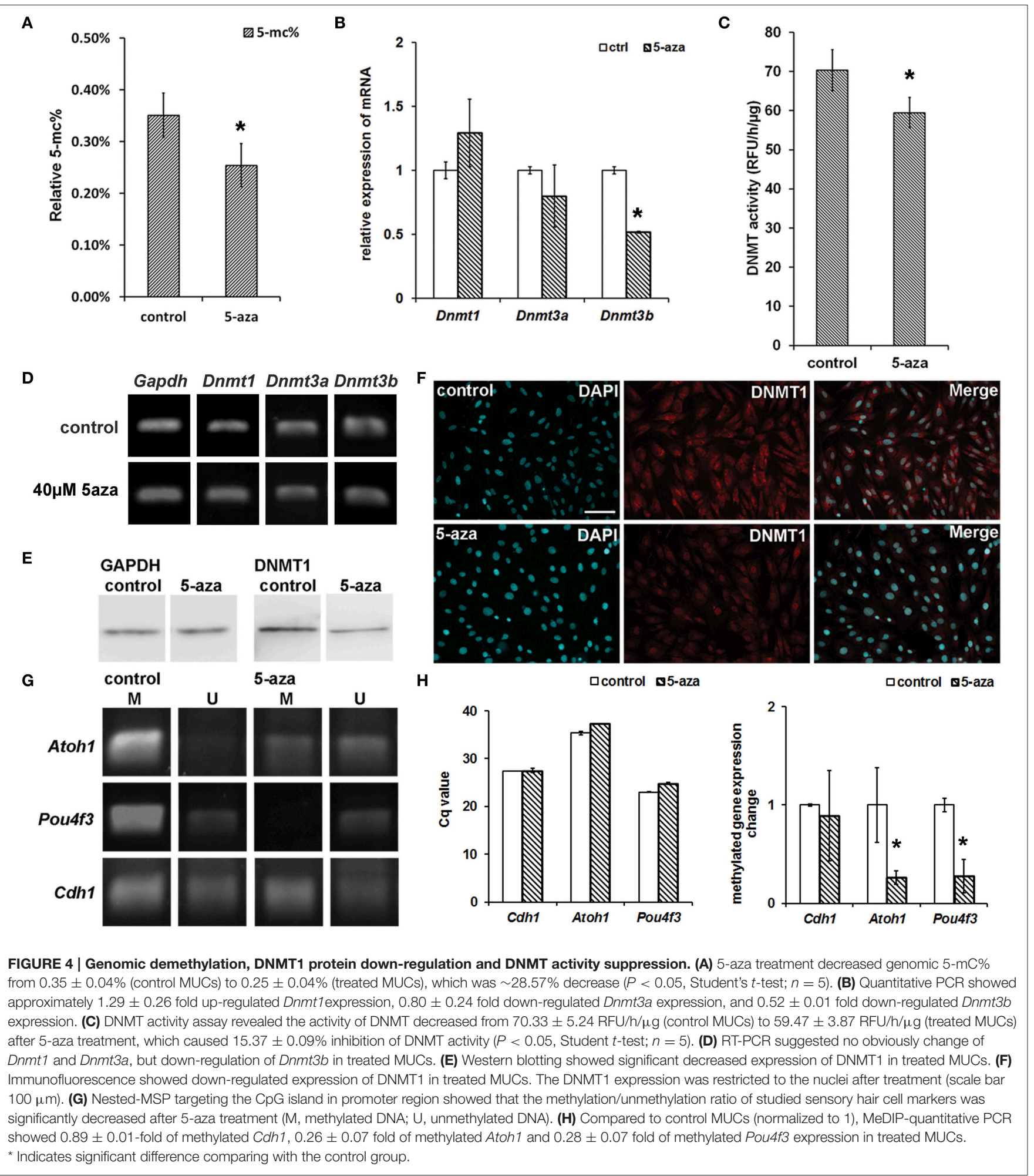

\section{DISCUSSION}

In this study, 5-aza was used to treat mouse utricle sensory epithelia-derived progenitor cell MUC. After the treatment, expression of prosensory genes, epithelial genes and hair cell genes was up-regulated. We found that 5-aza treatment caused increased protein expression of E-cadherin, Myosin VIIa, Myosin VI, and Pou4f3. FM1-43 permeation assay revealed that treated MUCs possessed the permeability of functional mechanotransduction channels. 5-aza significantly decreased 
DNMT1 protein expression and DNMT activity, by which the genome of MUCs underwent a remarkable demethylation process. Genomic methylation assays revealed that increased expression of sensory hair cell markers Atoh1 and Pou 4 f3 were likely resulted from DNA demethylation in their promoter regions.

5-aza is a DNMT inhibitor, which causes DNA demethylation by blocking DNMTs. Our study demonstrated that treated MUCs showed no obviously gene expression change of maintenance methyltransferase Dnmt1 and de novo methyltransferase Dnmt3a, but down-regulated expression of de novo methyltransferase Dnmt3b. However, the protein expression of DNMT1 was significantly decreased, and DNMT activity was remarkably reduced following 5-aza treatment. Down-regulated DNMT1 protein expression and decreased DNMT activity may contribute to the demethylation of MUC genome. Our result is consistent with previous studies, which suggested that DNA demethylation was caused by downregulated Dnmt gene and protein expression in cervical cancer, prostate cancer and acute leukemia cell lines (Chen et al., 2003; Walton et al., 2008; Lund et al., 2014). Additionally, our immunofluorescence study showed that DNMT1 mainly expressed in the cytoplasm of control MUCs, whereas its expression was reduced and translocated to the nuclei of treated MUCs. It has been reported that the intracellular localization of DNMT1 is various and is dependent on cell type, developmental stage, and pathological condition (Doherty et al., 2002; Ratnam et al., 2002; Lundberg et al., 2009; Desplats et al., 2011). In the current observation, DNMT1 translocation was observed in treated MUCs, but the mechanism of intracellular translocation is still obscure, which needs further investigation in our future studies. Overall, down-regulated DNMT1 protein expression and decreased DNMT activity may cause a remarkable demethylation in the genome of 5-aza-treated MUCs, which may contribute to the gene expression changes as discussed below.

Recent studies suggested that DNA demethylation may play an important role in stem cell reprogramming (Bagci and Fisher, 2013; Wongtrakoongate, 2015). For example, a differentiated cell line, normal adult basal prostatic epithelial (E-PZ) cells, could be reprogrammed and dedifferentiated into induced pluripotent stem cells by forced expression of embryonic pluripotent genes including Sox2, Oct4, and SSEA-3 (Zhao et al., 2013). The authors studied the methylation level of pluripotent genes and prostatic epithelial genes and found that during prostate differentiation, the methylation level of pluripotent genes elevated, whereas the methylation level of prostatic epithelial genes reduced, suggesting that DNA methylation plays an important role in stem cell differentiation (Zhao et al., 2013). In the present study using a tissue specific progenitor cell line MUC, we found that DNA methylation level was related to expression of prosensory genes such as Sox2 and Lfng. HMG-box transcription factor Sox2 is essential for sensory progenitor development in the mammalian inner ear including the differentiation of hair cell precursors. Sox 2 positive prosensory cells acquired an active expression of Atoh1, a transcription factor critical for hair cell differentiation, therefore determining the cell fate as hair cells (Locher et al., 2013). Overexpression of Sox2 in mouse otocyst induced sensory region specification, which subsequently stimulated prosensory cell differentiation and hair cell formation (Pan et al., 2013). It was reported that O-fucosylpeptide 3-beta$\mathrm{N}$-acetylglucosaminyltransferase, $L f n g$, was expressed in chicken otocysts and involved in the development of sensory organ in the inner ear development (Cole et al., 2000; Pujades et al., 2006). In the present study, 5-aza-induced DNA demethylation is likely to up-regulate expression of prosensory genes Sox2 and Lfng, which may be involved in guiding MUCs along a development program toward hair cell formation. Additionally, we observed other prosensory genes, including $B m p 4$ and $P 27^{k i p}$, changed their expression following treatment, suggesting that these prosensory genes may also be involve in the differentiation of MUCs.

In this study, control MUCs did not express epithelial genes Cdh1, Krt8, or hair cell gene Myo6, Atoh1, and Pou4f3. After 5-aza treatment, expression of these studied epithelial sensory hair cell genes was significantly increased. Protein expression of these epithelial sensory hair cell markers was elevated in treated MUCs in immunofluorescence and western blotting. FM1-43 permeation assays indicated that treated MUCs were permeable to FM1-43, which suggested that treated MUCs may possess some properties of mechanotransduction channels of sensory hair cells. Furthermore, the genomic methylation level of treated MUCs was significantly decreased. Expression of DNMT1 protein and the activity of DNMTs were downregulated following 5-aza treatment. To understand whether DNA methylation level influences hair cell gene expression, MSP, and MeDIP using primers targeting the promoter regions of hair cell genes were performed. The results revealed that relative expression of methylated Cdh1, Atoh1, and Pou 4 f3 was decreased and unmethylation of the promoter region of these genes was obviously increased after 5-aza treatment, which likely led to demethylation of the promoter region of studied genes, subsequently stimulated MUCs to upregulate expression of sensory hair cell genes and proteins, and finally contributed to differentiation of MUCs into hair cell-like cells. Our observation suggested that 5-aza treatment may be an approach to affect the methylation level of MUCs, and subsequently stimulates MUCs to differentiate into functional hair cell-like cells.

Compared to 5-aza-CdR that was used in our previous report (Zhou and $\mathrm{Hu}, 2015$ ), 5-aza seems to have better effects on sensory hair cell induction. In comparison of relative gene expression, majority of hair cell genes showed significant changes after 5-aza treatment. For instance, Atoh1, Espn, and Pou4f3 had $3.74 \pm 1.27,4.14 \pm 0.07,274.42 \pm 45.49$ fold increase after 5-aza treatment, but they did not show significant changes after 5-aza-CdR treatment. Further, 5-aza treatment stimulated hair cell protein expression including Myosin VIIa, Myosin VI, Pou4f3, and Math1, but 5-aza-CdR treatment did not cause obvious hair cell protein expression changes. Although 5-aza may cause adverse effects; however, no serious clinical complications and death attribute to 5-aza. Therefore, 5-aza has a preferable safety data and it has been approved by The Food and Drug Administration (FDA) for clinical therapy since 2004 
(Kaminskas et al., 2005). Based on these data, 5-aza treatment seems to exert a better role in inducing hair cell generation from MUCs.

In summary, the DNMT inhibitor 5-aza caused DNA demethylation in the entire genome of MUCs to induce cell lineage specification. In the treatment group, gene and protein expression of sensory hair cell markers was remarkably increased. The FM1-43 permeability assay indicated that treated MUCs may possess some properties of mechanosensory transduction channels, suggesting that treated MUCs had differentiated into hair cell-like cells. Nested-MSP and MeDIP-quantitative PCR revealed that up-regulation of sensory hair cell genes was likely caused by demethylation of the promoter region of these genes. Our study demonstrated a novel epigenetic approach in stem cell biology, which could induce tissue specific inner ear progenitors to differentiate into functional sensory hair cell-like cells. In the meantime, it opens avenues to develop strategies to guide tissue specific stem/progenitor cells to become functional cells without altering DNA sequence, which is

\section{REFERENCES}

Aimiuwu, J., Wang, H., Chen, P., Xie, Z., Wang, J., Liu, S., et al. (2012). RNAdependent inhibition of ribonucleotide reductase is a major pathway for 5azacytidine activity in acute myeloid leukemia. Blood 119, 5229-5238. doi: 10.1182/blood-2011-11-382226

Bagci, H., and Fisher, A. G. (2013). DNA demethylation in pluripotency and reprogramming: the role of tet proteins and cell division. Cell Stem Cell 13, 265-269. doi: 10.1016/j.stem.2013.08.005

Basner, M., Brink, M., Bristow, A., de Kluizenaar, Y., Finegold, L., Hong, J., et al. (2015). ICBEN review of research on the biological effects of noise 2011-2014. Noise Health 17, 57-82. doi: 10.4103/1463-1741.153373

Borodovsky, A., Salmasi, V., Turcan, S., Fabius, A. W., Baia, G. S., Eberhart, C. G., et al. (2013). 5-azacytidine reduces methylation, promotes differentiation and induces tumor regression in a patient-derived IDH1 mutant glioma xenograft. Oncotarget 4, 1737-1747. doi: 10.18632/oncotarget.1408

Bowers, R. R., Kim, J. W., Otto, T. C., and Lande, M. D. (2006). Stable stem cell commitment to the adipocyte lineage by inhibition of DNA methylation: role of the BMP-4 gene. Proc. Natl. Acad. Sci. U.S.A. 103, 13022-13027. doi: 10.1073/pnas.0605789103

Chen, C., Pan, D., Deng, A. M., Huang, F., Sun, B. L., and Yang, R. G. (2013). DNA methyltransferases 1 and $3 \mathrm{~B}$ are required for hepatitis $\mathrm{C}$ virus infection in cell culture. Virology 441, 57-65. doi: 10.1016/j.virol.2013.03.005

Chen, C. L., Liu, S. S., Ip, S. M., Wong, L. C., Ng, T. Y., and Ngan, H. Y. (2003). E-cadherin expression is silenced by DNA methylation in cervical cancer cell lines and tumours. Eur. J. Cancer 39, 517-523. doi: 10.1016/S0959-8049(02) 00175-2

Chen, J., Gao, Y., Huang, H., Xu, K., Chen, X., Jiang, Y., et al. (2015). The combination of Tet1 with Oct4 generates high-quality mouse-induced pluripotent stem cells. Stem Cells 33, 686-698. doi: 10.1002/stem.1879

Cole, L. K., Le Roux, I., Nunes, F., Laufer, E., Lewis, J., and Wu, D. K. (2000). Sensory organ generation in the chicken inner ear: contributions of bone morphogenetic protein 4, serrate1, and lunatic fringe. J. Comp. Neurol. 424, 509-520. doi: 10.1002/1096-9861(20000828)424:3<509::AIDCNE8 > 3.0.CO;2-Q

Desplats, P., Spencer, B., Coffee, E., Patel, P., Michael, S., Patrick, C., et al. (2011). Alpha-synuclein sequesters Dnmtl from the nucleus: a novel mechanism for epigenetic alterations in Lewy body diseases. J. Biol. Chem. 286, 9031-9037. doi: 10.1074/jbc.C110.212589

Doherty, A. S., Bartolomei, M. S., and Schultz, R. M. (2002). Regulation of stage-specific nuclear translocation of Dnmtlo during preimplantation mouse development. Dev. Biol. 242, 255-266. doi: 10.1006/dbio.2001.0534 fundamental to the design of future clinical trials involving human cells.

\section{AUTHOR CONTRIBUTIONS}

$\mathrm{YZ}$ and $\mathrm{ZH}$ designed the experiment, collected data, analyzed data, and wrote the main manuscript text. Both authors reviewed and final approved the manuscript.

\section{FUNDING}

This study is supported by R01DC013275 from NIDCD/NIH.

\section{ACKNOWLEDGMENTS}

The authors thank Fei Nei for her technique support, Xiaoyang Li for valuable comments to the manuscript, and Dr. James Richard Bartles, Northwestern University, for his generous supply of anti-Espin antibody.

Geleoc, G. S., and Holt, J. R. (2003). Developmental acquisition of sensory transduction in hair cells of the mouse inner ear. Nat. Neurosci. 6, 1019-1020. doi: $10.1038 / \mathrm{nn} 1120$

Guo, F., Li, X., Liang, D., Li, T., Zhu, P., Guo, H., et al. (2014). Active and passive demethylation of male and female pronuclear DNA in the Mammalian zygote. Cell Stem Cell 15, 447-458. doi: 10.1016/j.stem.2014.08.003

Hackanson, B., and Daskalakis, M. (2014). Decitabine. Recent Results Cancer Res. 201, 269-297. doi: 10.1007/978-3-642-54490-3_18

$\mathrm{Hu}, \mathrm{Z}$., and Corwin, J. T. (2007). Inner ear hair cells produced in vitro by a mesenchymal-to-epithelial transition. Proc. Natl. Acad. Sci. U.S.A. 104, 16675-16680. doi: 10.1073/pnas.0704576104

Jaenisch, R., and Bird, A. (2003). Epigenetic regulation of gene expression: how the genome integrates intrinsic and environmental signals. Nat. Genet. 33(Suppl.), 245-254. doi: 10.1038/ng1089

Jia, S., Yang, S., Guo, W., and He, D. Z. (2009). Fate of mammalian cochlear hair cells and stereocilia after loss of the stereocilia. J. Neurosci. 29, 15277-15285. doi: 10.1523/JNEUROSCI.3231-09.2009

Jones, P. A., and Takai, D. (2001). The role of DNA methylation in mammalian epigenetics. Science 293, 1068-1070. doi: 10.1126/science.1063852

Kaminskas, E., Farrell, A. T., Wang, Y. C., Sridhara, R., and Pazdur, R. (2005). FDA drug approval summary: azacitidine (5-azacytidine, Vidaza) for injectable suspension. Oncologist 10, 176-182. doi: 10.1634/theoncologist.10-3-176

Kelley, M. W. (2006). Regulation of cell fate in the sensory epithelia of the inner ear. Nat. Rev. Neurosci. 7, 837-849. doi: 10.1038/nrn1987

Kimura, S., Kuramoto, K., Homan, J., Naruoka, H., Ego, T., Nogawa, M., et al. (2012). Antiproliferative and antitumor effects of azacitidine against the human myelodysplastic syndrome cell line SKM-1. Anticancer Res. 32, 795-798.

Koehler, K. R., and Hashino, E. (2014). 3D mouse embryonic stem cell culture for generating inner ear organoids. Nat. Protoc. 9, 1229-1244. doi: $10.1038 /$ nprot.2014.100

Liyanage, V. R., Zachariah, R. M., and Rastegar, M. (2013). Decitabine alters the expression of Mecp2 isoforms via dynamic DNA methylation at the Mecp2 regulatory elements in neural stem cells. Mol. Autism 4:46. doi: 10.1186/20402392-4-46

Locher, H., Frijns, J. H., van Iperen, L., de Groot, J. C., Huisman, M. A., and Chuva de Sousa Lopes, S. M. (2013). Neurosensory development and cell fate determination in the human cochlea. Neural Dev. 8:20. doi: 10.1186/1749-8104$8-20$

Lund, K., Cole, J. J., VanderKraats, N. D., McBryan, T., Pchelintsev, N. A., Clark, W., et al. (2014). DNMT inhibitors reverse a specific signature of aberrant promoter DNA methylation and associated gene silencing in AML. Genome Biol. 15:406. doi: 10.1186/s13059-014-0406-2 
Lundberg, J., Karimi, M., von Gertten, C., Holmin, S., Ekstrom, T. J., and SandbergNordqvist, A. C. (2009). Traumatic brain injury induces relocalization of DNAmethyltransferase 1. Neurosci. Lett. 457, 8-11. doi: 10.1016/j.neulet.2009.03.105

Oesterle, E. C. (2013). Changes in the adult vertebrate auditory sensory epithelium after trauma. Hear. Res. 297, 91-98. doi: 10.1016/j.heares.2012.11.010

Okano, T., and Kelley, M. W. (2012). Stem cell therapy for the inner ear: recent advances and future directions. Trends Amplif. 16, 4-18. doi: 10.1177/1084713812440336

Orskov, A. D., Treppendahl, M. B., Skovbo, A., Holm, M. S., Friis, L. S., Hokland, M., et al. (2015). Hypomethylation and up-regulation of PD-1 in $\mathrm{T}$ cells by azacytidine in MDS/AML patients: a rationale for combined targeting of PD-1 and DNA methylation. Oncotarget 6, 9612-9626. doi: 10.18632/oncotarget.3324

Pan, W., Jin, Y., Chen, J., Rottier, R. J., Steel, K. P., and Kiernan, A. E. (2013). Ectopic expression of activated notch or SOX2 reveals similar and unique roles in the development of the sensory cell progenitors in the mammalian inner ear. J. Neurosci. 33, 16146-16157. doi: 10.1523/JNEUROSCI.3150-12.2013

Parker, M., and Bitner-Glindzicz, M. (2015). Republished: genetic investigations in childhood deafness. Postgrad. Med. J. 91, 395-402. doi: 10.1136/postgradmedj2014-306099rep

Pujades, C., Kamaid, A., Alsina, B., and Giraldez, F. (2006). BMP-signaling regulates the generation of hair-cells. Dev. Biol. 292, 55-67. doi: 10.1016/ j.ydbio.2006.01.001

Ratnam, S., Mertineit, C., Ding, F., Howell, C. Y., Clarke, H. J., Bestor, T. H., et al. (2002). Dynamics of Dnmtl methyltransferase expression and intracellular localization during oogenesis and preimplantation development. Dev. Biol. 245, 304-314. doi: 10.1006/dbio.2002.0628

Ronaghi, M., Nasr, M., and Heller, S. (2012). Concise review: inner ear stem cells-an oxymoron, but why? Stem Cells 30, 69-74. doi: 10.1002/stem.785

Rosca, A. M., and Burlacu, A. (2011). Effect of 5-azacytidine: evidence for alteration of the multipotent ability of mesenchymal stem cells. Stem Cells Dev. 20, 1213-1221. doi: 10.1089/scd.2010.0433

Sanz, L. A., Kota, S. K., and Feil, R. (2010). Genome-wide DNA demethylation in mammals. Genome Biol. 11:110. doi: 10.1186/gb-2010-11-3-110

Savary, E., Hugnot, J. P., Chassigneux, Y., Travo, C., Duperray, C., Van De Walter, T., et al. (2007). Distinct population of hair cell progenitors can be isolated from the postnatal mouse cochlea using side population analysis. Stem Cells 25, 332-339. doi: 10.1634/stemcells.2006-0303

Schneider-Stock, R., Diab-Assef, M., Rohrbeck, A., Foltzer-Jourdainne, C., Boltze, C., Hartig, R., et al. (2005). 5-Aza-cytidine is a potent inhibitor of DNA methyltransferase $3 \mathrm{a}$ and induces apoptosis in HCT-116 colon cancer cells via Gadd45- and p53-dependent mechanisms. J. Pharmacol. Exp. Ther. 312, 525-536. doi: 10.1124/jpet.104.074195
Song, D., Ni, J., Xie, H., Ding, M., and Wang, J. (2014). DNA demethylation in the PTEN gene promoter induced by 5-azacytidine activates PTEN expression in the MG-63 human osteosarcoma cell line. Exp. Ther. Med. 7, 1071-1076. doi: 10.3892/etm.2014.1571

Walton, T. J., Li, G., Seth, R., McArdle, S. E., Bishop, M. C., and Rees, R. C. (2008). DNA demethylation and histone deacetylation inhibition co-operate to re-express estrogen receptor beta and induce apoptosis in prostate cancer cell-lines. Prostate 68, 210-222. doi: 10.1002/pros.20673

Wheldon, L. M., Abakir, A., Ferjentsik, Z., Dudnakova, T., Strohbuecker, S., Christie, D., et al. (2014). Transient accumulation of 5-carboxylcytosine indicates involvement of active demethylation in lineage specification of neural stem cells. Cell Rep. 7, 1353-1361. doi: 10.1016/j.celrep.2014. 05.003

Wong, A. C., and Ryan, A. F. (2015). Mechanisms of sensorineural cell damage, death and survival in the cochlea. Front. Aging Neurosci. 7:58. doi: 10.3389/fnagi.2015.00058

Wongtrakoongate, P. (2015). Epigenetic therapy of cancer stem and progenitor cells by targeting DNA methylation machineries. World J. Stem Cells 7, 137-148. doi: 10.4252/wjsc.v7.i1.137

Zhang, L., and Hu, Z. (2012). Sensory epithelial cells acquire features of prosensory cells via epithelial to mesenchymal transition. Stem Cells Dev. 21, 1812-1821. doi: $10.1089 /$ scd.2011.0443

Zhao, H., Sun, N., Young, S. R., Nolley, R., Santos, J., Wu, J. C., et al. (2013). Induced pluripotency of human prostatic epithelial cells. PLoS ONE 8:e64503. doi: 10.1371/journal.pone.0064503

Zhou, G. S., Zhang, X. L., Wu, J. P., Zhang, R. P., Xiang, L. X., Dai, L. C., et al. (2009). 5-Azacytidine facilitates osteogenic gene expression and differentiation of mesenchymal stem cells by alteration in DNA methylation. Cytotechnology 60, 11-22|. doi: 10.1007/s10616-009-9203-2

Zhou, Y., and Hu, Z. (2015). Genome-wide demethylation by 5-aza-2'deoxycytidine alters the cell fate of stem/progenitor cells. Stem Cell Rev. 11, 87-95. doi: 10.1007/s12015-014-9542-z

Conflict of Interest Statement: The authors declare that the research was conducted in the absence of any commercial or financial relationships that could be construed as a potential conflict of interest.

Copyright (C) 2016 Zhou and Hu. This is an open-access article distributed under the terms of the Creative Commons Attribution License (CC BY). The use, distribution or reproduction in other forums is permitted, provided the original author(s) or licensor are credited and that the original publication in this journal is cited, in accordance with accepted academic practice. No use, distribution or reproduction is permitted which does not comply with these terms. 